\title{
Ensino de língua portuguesa por meio de variação linguística: Material de apoio
}

\author{
Édima de Souza Mattos
}

Unoeste

\author{
Raquel Tiemi Masuda Mareco \\ Unoeste
}

\begin{abstract}
Resumo
A pesquisa "Sociolinguística: a distância entre a fala coloquial e a norma culta no ensino médio", realizada em 2007, constatou e documentou uma grande distância entre a fala coloquial e a norma padrão em turmas de $1^{\text {a }}$ série de ensino médio de três unidades escolares do município de Presidente Prudente. Após análise dos resultados, criou-se uma apostila que serve como material de apoio à prática docente do professor de língua portuguesa do ensino médio. As atividades propostas contrastam o coloquialismo e a norma padrão, a fim de ensinar a norma culta por meio das diferenças.
\end{abstract}

Palavras-chave: sociolinguística, recurso metodológico, prática docente, ensino médio.

\section{INTRODUÇÃO}

A pesquisa "Sociolinguística: a distância entre a fala coloquial e a norma culta no ensino médio”, realizada em 2007, constatou e documentou grande distância entre o coloquialismo e a norma padrão em todos os conteúdos apresentados para avaliação. Como o questionário, base para a pesquisa, apresentava opções de fala coloquial e de norma padrão, ficou claro que os alunos não reconhecem a norma culta como recurso para comunicação.

A língua portuguesa ensinada na escola difere bastante da linguagem que o aluno traz de seu ambiente social. Essa diferença leva muitos alunos a acreditar que não sabem o português e que sua língua é difícil. Mas isso é, de fato, mais um “mito”, aceito por muitos como verdade (Bagno, 1999).

Utilizou-se o resultado da referida pesquisa para a elaboração de uma apostila, que visa a ensinar a língua portuguesa padrão por meio de variações linguísticas. A apostila traz 
atividades que contrastam linguagem coloquial e padrão, excluem pré-conceitos em relação ao que é certo ou errado e inserem conceitos de adequação linguística.

A ideia da elaboração da apostila surgiu da necessidade de uma metodologia diferenciada para o ensino da norma padrão, pois, somente por meio do ensino da mesma, o professor poderá criar oportunidades para alunos de classes desprivilegiadas a concorrerem, igualmente, com os alunos que convivem em ambientes onde a norma padrão é fluente e, ainda, em concursos e vestibulares.

\section{REVISÃO DE LITERATURA}

Certamente, as pessoas não falam como prescreve a norma culta da escrita da língua materna, pois se tratam de processos diferentes. Esses diferentes processos comunicacionais, com diversas intenções, propiciam a criação de vários tipos de linguagem que se agrupam em dois aspectos da língua: fala coloquial e fala culta. Fatores como o contexto, a intenção do usuário e a significação são responsáveis pela diferença entre a fala coloquial e a fala formal que, por sua vez, não estão estanques.

Segundo teorias sociolinguísticas, a língua sofre mudanças e variações com o tempo e no espaço, além de variar, também, de acordo com a situação social do falante. Mas, embora a Sociolinguística afirme que há uma liberdade de apropriação e expressão da língua pelo falante, a sociedade discrimina aqueles que cometem muitos deslizes no uso da norma culta em situações de comunicação.

Marcos Bagno (2001, p.40) afirma que o 'falar errado' pode criar uma baixa autoestima linguística: “os brasileiros em geral têm vergonha ou medo de falar e de escrever em situações um pouquinho mais formais porque acreditam que a língua que eles realmente conhecem não "serve" para essas situações”. Por outro lado, Marcuschi afirma:

[...] falar ou escrever bem não é ser capaz de aplicar regras da língua, mas é usar adequadamente a língua para produzir um efeito de sentido pretendido numa dada situação. Não se trata de saber como se chega a um texto ideal pelo emprego de formas, mas como se chega a um discurso significativo pelo uso adequado às práticas e à situação a que se destina (Marcuschi, 2007, p. 09). 
É importante considerarmos o fato de que a língua possui diversas variantes e que qualquer indivíduo pode aprender esta ou aquela para usá-la em seu convívio social. Ter o domínio de diversas variantes e fazer permutas entre elas de acordo com a necessidade social do falante enriquece o conhecimento sobre sua própria língua. Nas palavras de Luft:

Todas as variedades da língua são valores positivos. Não será negando-as, perseguindo-as,
humilhando quem as usa, que se fará um trabalho produtivo no ensino. Nem se mudarão em nada os
usos de níveis culturalmente inferiores, como equivocadamente alguns pensam. Cada falante fala
como sabe e consegue falar, não como ele ou outros desejariam que falasse [...] O importante é ter
bem claro que o aluno não precisa aprender a língua; precisa reforçar sua gramática implícita,
internalizada na primeira e na segunda infância, ampliá-la com elementos do modelo culto padrão e
precisa ter contato constante com bons textos, e descobrir, com o professor e toda a classe, as riquezas
expressionais do nosso idioma. O método natural no ensino da gramática consiste em, através de
técnicas e expedientes apropriados, levar o aluno a descobrir as regras que subjazem as formas, frases
e atos de comunicação, e aprender a enunciá-las, explicitá-las. Fazer o caminho inverso do
tradicional, que é dar e ditar regras, mandar decorar e obedecer. Na verdade, esse “descobrir regras” é
fazê-las vir à tona da consciência linguística, passar da intuição à reflexão e ao raciocínio (Luft, 1999,
p. 69).

Cada indivíduo possui uma gramática natural que lhe permite comunicar-se coerentemente. As crianças, mesmo antes de serem alfabetizadas, antes de saberem o que é um sujeito, um verbo, são capazes de construir enunciados coerentes e efetivos.

O ensino da norma culta a alunos de camadas desprivilegiadas tem por objetivo proporcionar-lhes o aprendizado de mais uma variedade linguística, a qual será adequada em algumas situações pelas quais a maioria das pessoas passa, tais como vestibular, entrevista para um emprego, etc. De acordo com Sacconi:

Um indivíduo só pode dizer-se livre no âmbito da comunicação lingüística, quando conhece várias modalidades de língua e escolhe aquela que melhor convém ao momento do discurso. É pouco conhecer apenas uma língua funcional ou a sua variante sociolinguística. O ideal é que o indivíduo seja poliglota dentro de sua própria língua. [...] Conhecer a norma culta é sentir-se mais livre para comunicar-se. A norma culta pode comparar-se à etiqueta social: não é preciso usá-la para viver, mas é absolutamente indispensável conhecê-la para conviver (Sacconi, 2003, p.03).

Ao estar em contato constante com diversas variedades, inclusive a padrão, o aprendiz tem diante de si, formas linguísticas a sua escolha, para qualquer contexto ou situação (Carvalho, 2005, p. 50). Assim, a educação linguística deve ser uma constante preocupação do professor de língua, principalmente frente a essa forte influência dos meios de comunicação de massa.

Aceitar a linguagem que o aluno traz de seu meio social não quer dizer que não se deve ensinar a norma padrão e deixar que o aluno seja livre para usar a linguagem que quiser em qualquer situação. Segundo o autor Marcos Bagno (2001), devemos ensinar a norma padrão, mas ensinar a norma padrão é diferente de ensinar a gramática tradicional. O 
professor deve manter o aluno em contato permanente e intenso com textos falados e escritos para que ele possa depreender esses recursos.

É importante ter em mente que nem tudo o que se escreve se pronuncia, assim como nem tudo que se pronuncia se escreve [...] Podemos dizer ao aluno que ele pode falar bonito ou bunito; menino ou minino, mas só pode escrever bonito e menino, porque é preciso uma ortografia única para toda a língua, para que todos possam ler e compreender o que está escrito (Bagno, 2001, p. 87, 104).

\section{CONTEXTO}

A pesquisa "Sociolinguística: a distância entre a fala coloquial e a norma culta no ensino médio” foi realizada em três escolas públicas estaduais localizadas no município de Presidente Prudente - SP.

Dentre as unidades escolares envolvidas, duas são de bairros periféricos e uma do centro da cidade, porém constatou-se que a localização das escolas não influenciou nos resultados, pois os alunos das três unidades são oriundos de bairros periféricos e pertencem a comunidades discursivas semelhantes.

A escolha de alunos de primeira série deveu-se ao fato de o professor ter tempo para diminuir possíveis dificuldades antes de os alunos saírem do ensino médio.

\section{PROCEDIMENTOS METODOLÓGICOS}

A pesquisa intitulada "Sociolinguística: a distância entre a fala coloquial e a norma culta no ensino médio”, realizada no ano de 2007, constatou e documentou uma grande distância entre a fala coloquial e a norma padrão em turmas de $1^{\mathrm{a}}$ série de ensino médio de três unidades escolares localizadas no município de Presidente Prudente. Essa constatação se deu por meio de análise de um questionário, sem identificação, com cinquenta situações de fala, aplicado a 256 alunos. 
Diante disso, elaborou-se uma apostila com atividades que contrastam o coloquialismo e a norma padrão, a fim de ensinar a norma padrão por meio das diferenças.

Os resultados da pesquisa e a apostila foram entregues às três escolas envolvidas, com o intuito de conscientizar o professor de língua portuguesa sobre as dificuldades de seus alunos e apresentar sugestões de solução.

Vale ressaltar que a referida apostila não é um material didático, portanto não é completa em relação aos conteúdos a serem trabalhados no ensino médio. Ela é, na realidade, um material de apoio para que o professor trabalhe, de forma diferenciada, conteúdos em que os alunos têm mais dificuldades, conforme constatou a pesquisa.

A apostila contém quinze unidades, cada uma com um tema e várias atividades, além de planos de aula e gabaritos.

Devido à impossibilidade de mostrarmos a referida apostila na íntegra, apresentaremos aqui três unidades completas, a fim de proporcionar ao leitor uma visualização do até então dito.

\section{APOSTILA}

\section{Plano de Aula 1 - Norma Padrão}

Série: $2^{\circ}$ ou $3^{\circ}$ ano do ensino médio

Objetivos específicos: possibilitar o contato com a norma padrão por meio de vocábulos que rimam.

Conteúdo: rimas no poema; a norma padrão na criação literária.

Recursos: letra da música: Rosa, de Pixinguinha

(Opcional: áudio com a música Rosa de Pixinguinha interpretada por Marisa Monte).

Duração: 100 minutos - duas aulas.

\section{Desenvolvimento metodológico (procedimentos)}

I. O professor faz uma breve explicação sobre rimas. 
II. Atividade 1: os alunos lêem uma letra de música, que segue a norma padrão, e tentam completá-la com palavras que julgarem adequadas (observando as rimas).

III. O professor toca o áudio para fazer a correção da atividade 1.

IV. O professor abre uma discussão sobre o contraste do vocabulário utilizado na letra da música e o vocabulário coloquial cotidiano.

V. O professor pede que eles façam os exercícios de 2 a 5 . Disponibiliza alguns dicionários, caso eles queiram verificar.

VI. O professor faz a correção oralmente, considerando várias possibilidades de respostas do exercício 3 em diante.

\section{Sugestão}

O professor pode trabalhar também outros aspectos da linguagem culta, tais como orações em ordem indireta, conjugação verbal etc.

\section{Gabarito}

\section{Atividade 2}
a) Olor
f) Sepultas
k) Unção
b) Clemente
g) Olentes
l) Remir
c) Lanceado
h) Dolentes
m) Padecer
d) Arfante
i) Resplendor
n) Fenecer
e) Perenal
j) Onipotente

\section{ROSA}

(Pixinguinha/Otávio de Souza)

A - Tu és, divina e graciosa

A - Estátua majestosa

B - do amor

C - Por Deus esculturada

B - E formada com ardor

B - Da alma da mais linda flor

B - De mais ativo olor

B - Que na vida é preferida pelo beija-flor

A - Se Deus me fora tão clemente
A - Aqui nesse ambiente

B - de luz

C - Formada numa tela

C - deslumbrante e bela

D - Teu coração junto ao meu lanceado

D - Pregado e crucificado

B - sobre a rósea cruz

E - do arfante peito teu

A - Tu és a forma ideal 
A - Estátua magistral

A - Oh alma perenal

B - Do meu primeiro amor, sublime amor

B - Tu és de Deus a soberana flor

C - Tu és de Deus a criação

C - Que em todo coração

B - sepultas um amor

$\mathrm{B}$ - O riso, a fé, a dor

D - Em sândalos olentes

B - cheios de sabor

B - como um sonho em flor

D - Em vozes tão dolentes

A - És láctea estrela

B - És mãe da realeza

C - És tudo enfim que tem de belo

B - Em todo resplendor da santa natureza
A - Perdão, se ouso confessar-te

A - Eu hei de sempre amar-te

B - Oh flor meu peito não resiste

B - Oh meu Deus o quanto é triste

C - A incerteza de um amor

D - Que mais me faz penar

D - em esperar

D - Em conduzir-te um dia ao pé do altar

A - Jurei, aos pés do onipotente

A - Em preces comoventes

B - de dor

C - E receber a unção

C - da tua gratidão

D - Depois de remir meus desejos

D - Em nuvens de beijos

E - Hei de envolver-te até meu padecer

E - De todo fenecer

\section{ATIVIDADES - Aula 1}

1 - Leia a letra da música e complete os espaços observando as rimas.

\section{$\underline{\text { ROSA }}$}

(Pixinguinha/Otávio de Souza)

A - Tu és, divina e

A - Estátua majestosa

B - do

C - Por Deus esculturada

B - E formada com ardor

B - Da alma da mais linda

B - De mais ativo olor

B - Que na vida é preferida pelo beija-flor
A - Se Deus me fora tão clemente

A - Aqui nesse

B - de luz

C - Formada numa tela

C - deslumbrante e

D - Teu coração junto ao meu lanceado

D - Pregado e

B - sobre a rósea cruz

E - do arfante peito teu 
A - Tu és a forma

A - Estátua magistral

A - oh alma perenal

B - Do meu primeiro amor, sublime amor

B - Tu és de Deus a soberana flor

C - Tu és de Deus a

C - Que em todo coração

B - sepultas um amor

$\mathrm{B}$ - O riso, a fé, a

D - Em sândalos olentes

B - cheios de

B - como um sonho em flor

D - Em vozes tão dolentes

A - És láctea estrela

B - És mãe da realeza

C - És tudo enfim que tem de belo

B - Em todo resplendor da santa
A - Perdão, se ouso confessar-te

A - Eu hei de sempre

B - Oh flor meu peito não resiste

B - Oh meu Deus o quanto é

C - A incerteza de um amor

D - Que mais me faz penar

D - em

D - Em conduzir-te um dia ao pé do

A - Jurei, aos pés do onipotente

A - Em preces comoventes

B - de dor

C - E receber a unção

C - da tua

$\mathrm{D}$ - Depois de remir meus

D - Em nuvens de beijos

E - Hei de envolver-te até meu padecer

$\mathrm{E}$ - De todo fenecer

2 - Encontre no texto as palavras para as seguintes definições:
a) Aroma, perfume, fragrância:
b) Indulgente, bondoso, piedoso:
c) Ferido com lança:
d) Ofegante, palpitante:
e) Que dura muitos anos, eterno, incessante:
f) Enterras, soterras:
g) Perfumados, aromáticos:
h) Lamentosas, lastimosas:
i) Brilho intenso:
j) Que tudo pode, que tem poder absoluto, todo-poderoso:
k) Sentimento de piedade:
l) Resgatar, adquirir de novo: 
m) Sofrer, suportar agüentar:

n) Findar, extinguir-se, morrer, terminar, acabar:

3 - Reescreva as orações em que aparecem as palavras do exercício 1 com palavras sinônimas.
a)
b)
c)
d)
e)
f)
g)
h)
i)
j)
k)
l)
$\mathrm{m})$
n)

4 - O texto de Pixinguinha foi escrito de acordo com as regras da norma padrão. Retire do texto 3 trechos que comprovem essa afirmação.

a)

b)

c)

5 - Reescreva os trechos do exercício 3 na linguagem coloquial que você utilizaria em seu dia-a-dia.

a)

b)

c)

Plano de Aula 2 - Marcas de Plural, Troca do LH pelo I e Concordância Verbal 
Série: $2^{\circ}$ ou $3^{\circ}$ ano do ensino médio

Objetivos específicos: entendimento da concordância verbal e das flexões necessárias para construir enunciados no plural; corrigir pronúncias, por meio de exercícios de audição.

Conteúdo: concordância verbal; marcas de plural.

(Opcional: Áudio: música Cuitelinho de Nara Leão interpretada por Milton Nascimento; ou por Rio Negro e Solimões).

Duração: 100 minutos - duas aulas (geminadas).

\section{Desenvolvimento metodológico (procedimentos)}

I. O Professor entrega as fotocópias com a letra da musica Cuitelinho.

II. Toca o CD com a música interpretada por Milton Nascimento (que é fiel ao texto escrito).

III. Abre discussão sobre o que os alunos acham que acontece naquela letra de música; é possível compreendê-la? Que tipo de linguagem foi usada?

IV. O professor faz uma breve explicação sobre concordância verbal.

V. Os alunos fazem os exercícios propostos.

VI. Para fazer a correção o professor toca o CD com a música interpretada por Rio Negro e Solimões (que aplica os plurais e a concordância de acordo com a norma padrão)

\section{ATIVIDADES - AULA 2}

Leia a letra da música, abaixo.

\section{CUITELINHO}

(Folclore recolhido por Paulo Vanzolini e Antônio Xandó)

Cheguei na beira do Porto onde as onda se espaia

As garça, dá meia volta, senta na beira da praia

E o Cuitelinho não gosta, que um botão de rosa cáia, ai, ai

Ai quando eu vim da minha terra, despedi da parentaia

Eu entrei no Mato Grosso, dei em terras Paraguaia

Lá tinha revolução, enfrentei fortes bataia, ai, ai

A tua saudade corta como aço de navaia

O coração fica aflito, bate uma a outra faia

E os óio se enche d'água, que até a vista se atrapaia, ai, ai 
1 - A letra de música mostrada acima apresenta desvios em relação à norma padrão nos seguintes conteúdos: plural, troca do lh pelo i, concordância verbal entre outros. Complete a tabela com os desvios e coloque-os na norma padrão.

\begin{tabular}{|l|l|}
\hline \multicolumn{2}{|c|}{ Concordância Verbal } \\
\hline Português Não Padrão & \\
\hline & \\
\hline & \\
\hline & \\
\hline & \\
\hline
\end{tabular}

\begin{tabular}{|l|l|}
\hline \multicolumn{2}{|c|}{ Plural } \\
\hline Português Não Padrão & \\
\hline & \\
\hline & \\
\hline & \\
\hline & \\
\hline
\end{tabular}

\begin{tabular}{|l|l|}
\hline \multicolumn{2}{|c|}{ Troca do LH pelo I } \\
\hline Português Não Padrão & \\
\hline & \\
\hline & \\
\hline & \\
\hline
\end{tabular}

2 - Reescreva as frases de acordo com a norma padrão, com o inicio proposto, sem mudar o sentido.

Ex: na beira do Porto onde as onda se espaia As Ondas se espalham na beira do porto.

a) Quando eu vim da minha terra, despedi da parentaia.

Despedi

b) A vista se atrapaia.

A vista fica

3 - Há no texto um desvio de regência verbal. Escreva a oração em que ele se encontra. 
4 - Escreva a oração na qual se encontra o maior numero de desvios, em relação à norma padrão.

\section{Plano de Aula 3 - Candidato à Presidência}

Série: $2^{\circ}$ ou $3^{\circ}$ ano do ensino médio

Objetivos específicos: desenvolver a oralidade, a argumentação e a conscientização em relação à política e ao voto, além de reconhecer a variedade linguística que deverá ser utilizada.

Conteúdo: texto oral criado pelos alunos.

Duração: 200 minutos - quatro aulas, ideal que sejam duas e duas em dias diferentes, pois essa aula é dividida em duas partes.

\section{Desenvolvimento metodológico (procedimentos)}

I. O professor divide a sala em grupos.

II. Faz uma breve explicação de algumas técnicas de oratória, tais como; postura corporal, entonação, etc.

III. Explica que eles serão um político, candidato a presidente, portanto devem falar sobre as melhorias que farão no país, caso eleitos e, que setores serão beneficiados (saúde, educação, trabalho, etc.).

IV. Sugere que os alunos não devem exagerar nas promessas, e propor somente o que for possível fazer.

V. Dá um tempo para discutirem com o grupo o que vão falar e propõe a apresentação (um aluno de cada grupo representará o candidato a presidente).

VI. Depois de todos os grupos terem apresentado, o professor faz uma eleição real; distribui cédulas e cada aluno deve escrever o número do candidato o qual votaria.

VII. Se houver tempo o professor pode discutir com a sala sobre o resultado. Por que aquele candidato ganhou? Será que as propostas dele eram melhores ou ele soube se expor e argumentar melhor?

\section{Sugestões}

O professor pode premiar o grupo cujo candidato foi o vencedor. 


\section{CONSIDERAÇÕES FINAIS}

O ensino de língua portuguesa consiste em não impor ao aluno a língua culta como única maneira de se expressar, nem deixá-lo cair no coloquialismo, utilizando a linguagem que quiser em qualquer situação.

O fato de o coloquialismo ser mais freqüente do que a linguagem formal, no dia-a-dia dos adolescentes, faz com que eles considerem a norma culta como “estranha”.

Para introduzirmos a norma padrão na vida desses adolescentes, sugerimos a leitura e o constante contato com textos que seguem a norma padrão, bem como possibilitar aos alunos situações de fala e de escrita que visem ao uso de uma linguagem mais apurada.

Como auxílio ao professor nesse grande desafio, propomos a apostila citada neste trabalho, não como um material imposto, mas como uma opção a mais para o professor de língua portuguesa.

Espera-se que, além de utilizar as atividades propostas, os professores (re)criem outras e/ou adaptem as mesmas à realidade de sua sala de aula.

\section{REFERÊNCIAS}

Andre, H. A. (1997). Gramática ilustrada. São Paulo: Moderna.

Bagno, M. (2001). Português ou brasileiro? Um convite à pesquisa. São Paulo: Parábola.

--------. (2001). A Língua de Eulália. Novela sociolingüística. São Paulo: Contexto. (2002). Preconceito lingüístico: o que é? Como se faz? São Paulo: Loyola.

Bueno, S. (2000). Mini-Dicionário da língua Portuguesa. São Paulo: FTD.

Barroso, M. E. G. (1999). Dicionário Aurélio eletrônico - SÉCULO XXI. São Paulo - SP Lexikon Informática LTDA.

Carvalho, M. C. M. (2005). Concordância verbal e variação no ensino fundamental e médio. Dissertação de Mestrado inédita. Universidade Estadual de Londrina.

Kock, I. V. \& Travaglia, L. C. (1990). A coerência textual. São Paulo: Contexto. 
Marcushi, L. A. (2007). Da fala para a escrita: Atividades de textualização. São Paulo: Cortez.

Sacconi, L. A. (2003). Não erre mais. São Paulo: Atual.

Simões, D. et al. (2007). Português se aprende cantando. Rio de Janeiro: Dialogarts.

\begin{abstract}
AS AUTORAS
Édima de Souza Mattos é professora titular da Unoeste - Universidade do Oeste Paulista. Compõe o corpo docente dos cursos de graduação em Letras e Comunicação Social. Sua área de pesquisa envolve linguística, sociolinguística, língua portuguesa, com ênfase em educação e cultura.E-mail: edimamattos@bol.com.br.

Raquel Tiemi Masuda Mareco é graduada em Letras pela Unoeste - Universidade do Oeste Paulista e cursa, na condição de aluna especial, uma disciplina no Programa de Mestrado em Estudos da Linguagem da UEL - Universidade Estadual de Londrina. Seu foco de pesquisa é em sociolinguística, língua portuguesa. E-mail: rachelmareco@hotmail.com.
\end{abstract}

